WORK IN PROGRESS

\title{
Integrating Business Analytics into SMEs in Mexico: Challenges and Opportunities
}

\author{
Jorge Luis Fernandez, Juan Edel Gutierrez, Luis A. \\ Castro, Luis-Felipe Rodríguez
}

Published: 21 September 2016

\begin{abstract}
Entrepreneurs in Mexico start their businesses out of need, based on good ideas or to accomplish a "dream". Nonetheless, starting out a business is not an easy task. Usually, business owners lack either professional background or financial knowledge, and focus only on keeping the business afloat, while trying to obtain profits. Business Intelligence and Analytics serve a great purpose in the growth of any company, but it is usually left out or ignored by small or medium enterprises, due to a lack of knowledge or because owners do not consider it necessary for a mid to long term plan. In the long run, businesses usually fail to achieve profit or cannot continue, and end up not knowing what went wrong. The information that a business generates could serve as a starting point for good and solid decision making, but the culture that dominates small and medium enterprises on any industry leaves important information unrecorded or unattended, forcing them to work based only on trial and error.
\end{abstract}

Keywords: SME; Business Analytics; Business Intelligence, POS; Inventory Tracking.

\section{Introduction}

With the advent of information technology in organizations, the world of organizations has been generating large amounts of data and information. Large companies are requiring more storage technology based on the need to increase information storage capacities. In this sense, some of the questions that remain unanswered are: why some organizations are not taking advantage of all the generated data? Are all the data being utilized? The answer to these questions can be difficult to come by, even in industrialized countries. In the case of Mexico, the answer to these questions can be even more evasive. At least in Mexico, there are many cases wherein the information available for decision making in organizations is often misleading, inaccurate and tardy. For this, there are multiple ways to take advantage of all the data stored on a daily basis, and one of them is achieved through Business Intelligence (BI). This allows companies to exploit all

Fernandez, JL., Gutierrez, JE., Castro, LA., Rodríguez, LF.

Dept. of Computing and Design

Sonora Institute of Technology (ITSON)

Ciudad Obregon, Mexico

Email: jorgefdez@live.com, juanedelgtz@gmail.com,

luis.castro@acm.org, luis.rodriguez@itson.edu.mx available data to grasp opportunities, and avoid mishaps [1].

According to [2], Business Intelligence could be defined as a "way to support decision making with information and valuable knowledge by leveraging a variety of data sources as well as structured and unstructured information". Previous studies have been conducted in the field of BI, and it has been found that BI tools are really useful to streamline key processes of organizations. This is due to the magnitude and complexity of decisions required by each process [3]. Thanks to this, managers can respond easily to the company's needs and questions that management could pose. For example: What was the performance of the Production department this month? How are my sales doing? What can I do to sell more? How can I anticipate the future? How can I create a competitive advantage over the competition? What is my financial situation? [4].

In this paper, we provide an overview of the challenges and opportunities that could arise with Small and Medium Enterprises (SMEs) in Mexico when a BI solution is designed. We present a case study carried out in northwest Mexico with a SME in the restaurant industry. In this case study, as we will highlight throughout this paper, the lack of experience in data management and planning, and the limited resources that this company has serve as a prime example of the state of several SMEs in Mexico.

\section{Related work}

Previous studies and proposals allow us to observe and analyze cases that have been carried out to optimize or improve performance in key business processes. For example, in [5], the authors demonstrate how the supply chain is optimized by including the use of Business Analytics (BA) in the redesign of the supply chain process, obtaining several benefits such as improvement in performance, better use of resources and avoiding down time [5].

In addition, the case of Bayer is also worth mentioning. Bayer is a German multinational chemical and pharmaceutical company that needed to consolidate the processes carried out in different countries where the company operates, and to reduce errors by manual data entry in different formats. In order to do so, it had to be able to merge and manage multiple tools and data sources, resulting from the large number of acquisitions made since 2005 by Bayer. To ameliorate this problem, IBM offered Cognos BI solutions and implemented them alongside KM (Knowledge Management), IBM's business associate. As of 2016, Cognos BI has been deployed in 8 countries and there are plans to continue expanding. This optimization allowed the immediate availability 
of market information for rapid decision-making, standardization of reports, cubes and dashboards, and allowed reduced infrastructure, licensing and consulting costs. Now, thanks to the IBM solution, negotiations with suppliers are centralized and support costs have been significantly reduced [6].

Another case that has been reported is the case of Sbarro Inc., one of the main Italian-American cuisine restaurants in the United States (US). In 2005, Sbarro rolled out an above-store reporting system called Aloha Enterprise to more than 400 locations. The Aloha Enterprise system works in conjunction with the chain's Aloha by Radiant Systems point of sale software and hardware, and it worked by copying, on an hourly basis, in-restaurant data to a centrally hosted database augmented by analytical tools and reporting capabilities. Before the rollout, the data were received once a week and generated late reactions and decisions. Nowadays, the information is available and ready to analyze every hour. At the same time, a reduction on food and labor costs was met, while also detecting dishonest employees, theft and employee coaching needs. Nonetheless, one of the most important changes recognized by them was "corporate culture" [7].

Also, the Einstein Noah Restaurant Group moved managers from reports on spreadsheets to functional dashboards that displayed store performance data. Needless to say, the implementation received very positive feedback. With nearly 7,000 employees at approximately 860 locations in the US, the Einstein Noah Restaurant Group is the nation's largest operator of bagel bakeries. As part of a 2013 BI initiative to migrate from Excel-based reporting, they started to build and populate a new enterprise data warehouse by employing agile development methods, adding also a mobile enterprise analytics project with Microstrategy, a provider of business intelligence, mobile software, and cloud-based services. Qlikview and Microsoft SQL would still be used, but Microstrategy was meant as the focus point of the BI strategy. The plan is to move all data sources into a data warehouse, enabling better data governance, including master data management. Future plans are now focused on incorporating information, such as store audit data, in the data warehouse to have them readily available through the MicroStrategy app, therefore allowing business managers to easily plug in information from a store site into a dashboard on mobile technology, such as tablets [8].

Red Robin International Inc., a chain of casual dining restaurants, had different cross-data databases in Microsoft Access, which referred to the same product with different codes. This made it nearly impossible to compare sales and costs, which in turn caused a weekly mismatch of thousands of dollars when calculating costs. By carrying out a process that involved cleaning information, while also providing data quality, financial reports were balanced, and managers were able to generate reports and menus based on customer preferences, calculate the ideal cost of each product, review profit margins and were eve able to generate savings by tracking lower costs and offers on raw materials with different providers [9].

In 2012, El Pollo Loco Inc., a restaurant chain specializing in Mexican-style grilled chicken in the US, was able to review the latest data on limited-time offers, as well as the performance of new products. The company invested $\$ 250,000$ USD in 2010 with IBM Corp.'s Cognos BI software to be able to "rack and stack numbers" [10]. This translated in easier, faster data comparison across the company's 401 restaurants, 58\% of which are franchised. After the implementation, the company showed a $9.9 \%$ increase in same-store sales and $9 \%$ boost system-wide in
2012, reaching $\$ 607$ million USD in sales, regaining the company's profitability [10].

\section{SMEs in Mexico: An overview}

Every day, SMEs are created in Mexico. According to ProMéxico, with data from the National Institute of Statistics and Geography (INEGI) in Mexico, there are just over 4 million businesses. From those, $99.8 \%$ are SMEs, which generate $52 \%$ of gross domestic product (GDP) and 7 of every 10 jobs across the country. This indicates that SMEs are the support for development and industrial growth in Mexico [11]. However, 52.5\% of SMEs in Mexico tend to last less than 2 years, mainly due to the inability to be profitable [16].

This growth and the direct business management by the owners, together with the inexperience in information systems, have led companies to incorrect implementations and the misuse of data generated in daily operations like average ticket amount, purchasing and acquisitions, sales by product, staff performance, and the like.

In addition, the lack of formal data entry and data analysis has led to several problems, such as missing inventory, losses due to material waste, partial solutions and confusion from both staff and owners, despite any sale success a company may have. All this adds up to problems and failure to comply with customer demands.

These problems are just a part of bigger ones that currently affect SMEs in Mexico. Some of the most compelling problems are: lack of strategic planning, problems between owners of a familyowned businesses, little to no business and financial background, no employee development, lack of a formal hiring and training process, excessive and unneeded expenditures, low or null IT investment. Although there may be others, these are some of the main problems that negatively affect SMEs. These problems, altogether, make it harder for their owners and managers to envision the need for a BI solution. Even more, the possibility of accessing specialized financial programs for SMEs can be greatly increased by having control and knowledge of operational and financial information readily accessible [15].

\section{Methods}

In this work, we carried out a mixed-methods approach that includes a case study with a SME in the restaurant industry in a mid-size city in northwest Mexico (Pop. around 500,000 inhabitants).

\subsection{Research procedure}

As part of the study, we carried out continual interviews with business owners and systematic analysis of business processes to fully understand their current situation, their vision as a company, the existing processes, as well as their mid-term goals.

In particular, business owners and staff were weekly interviewed for 8 weeks as well as several visits to the restaurant's different areas and personnel. This allowed us to review the history and growth of the business, basic business processes, and their issues in inventory keeping, sales control, cost reduction, personnel management, and desired profit margins.

\subsection{Case study}

This research was conducted in a SME of the restaurant industry, with 4 locations in a single city and about 100 full-time employees. This business was founded in 2005 as a food truck, slowly growing in popularity among locals. After two years, the business moved to its first brick-and-mortar location. In 2010, 
they started a steady local expansion, opening their first branch, which eventually became their headquarters due to its strategic location and growing popularity. By the end of 2013, the third location was established, providing service to the southern part of the city. In 2015, by the 10th anniversary, they decided to open their fourth restaurant location with a new Restaurant/Bar concept, to appeal to a broader customer base.

All this growth was informally carried out, running numbers on pen and paper, which was later transferred to spreadsheets. By the end of 2012, according to the owner's own accounts, they felt the need to integrate a Point of Sale (POS) and Management System software, but only to speed up the customer order process. None of the remaining Business Processes are being supported by the current system.

Even though competition is high (approximately 7 direct competitors with a similar concept), safety and health standards are reportedly higher than that of their direct local competitors. According to the owner, this is at the top of their priorities. Nonetheless, the lack of historical records and transactional information makes it harder to continue on a steady growth rate. Without those, the company managed to grow based only on trial and error, while tackling problems such as: process duplicity, overstaffing, down times due to lack of resources, order misplacement, unbalanced workloads, excessive product waste, theft, and the need to have an owner/family member always on site to solve any and all problems. By having a historical record and taking advantage of it, the owners could have better strategies and resource planning, making the operation more efficient and more reliable decisions could be made.

From the business web site, the company's mid-term vision is "to strengthen each of the existing branches and position ourselves as leaders in the region, being recognized for quality, taste and fast service. To achieve expansion outside the city and position the brand in Northwestern Mexico."

Currently, the management system and POS software lacks a complete and clean installation, meaning that some common system errors are erroneous menus, duplicate articles, zero inventory management and discrepancies in customer tickets, and the like. This, in turn, leaves them unaware of the exact sales numbers and statistics, purchases being made and inventory control, especially on a daily basis. Controls sales are in currently spreadsheets, captured fully manually. Also, the front desk computer accesses the system through the network, which is installed onto a regular PC that is used as a server. This hardware issue regularly causes data entry errors and frequent system crashes.

\section{Results}

Throughout the sessions with owners and staff members, deficiencies in the management of information were found, and the need to carry out a proper implementation of the existing management system was raised. This would enable them to take full advantage of the sales and inventory control features, meaning that the captured data could be analyzed through a BI system.

To illustrate this, the analysis of the purchasing process "as is" identified two problems: attention to inefficient inventory level raw material and lack of proper inventory transaction records. Consequently, a new business process model "as it should be" should focus on real-time inventory levels to avoid losses or missing items. In addition, it should generate the appropriate historical records to be retrieved in an accessible manner with the support of BI.
As a result of the analysis performed, a SIPOC diagram of the "as is" purchasing process (Table 1) is presented. The SIPOC diagram is a tool used in the Six Sigma methodology, which focuses on Suppliers, Inputs, Process, Outputs, and Customers, thus deriving its name. The SIPOC diagram is used to mainly identify the suppliers, inputs, activities, records and staff involved in the process of purchasing raw material. A SIPOC diagram is used to identify relevant elements of a process improvement project.

Table 1. Purchasing process SIPOC diagram

\begin{tabular}{|c|c|c|c|c|}
\hline Supplier & Input & Process & Output & Customer \\
\hline Chef & Checklist & $\begin{array}{l}\text { Register } \\
\text { Order }\end{array}$ & $\begin{array}{c}\text { Order } \\
\text { Registered }\end{array}$ & Manager \\
\hline Manager & $\begin{array}{l}\text { Registered } \\
\text { Order }\end{array}$ & Approval & $\begin{array}{l}\text { Authorized } \\
\text { Order }\end{array}$ & Cashier \\
\hline Cashier & $\begin{array}{l}\text { Authorized } \\
\text { Order }\end{array}$ & Send Order & Sent Order & Supplier \\
\hline Supplier & Sent Order & $\begin{array}{l}\text { Prepare } \\
\text { Order }\end{array}$ & $\begin{array}{l}\text { Packed } \\
\text { Order }\end{array}$ & Manager \\
\hline Manager & $\begin{array}{l}\text { Packed } \\
\text { Order, } \\
\text { Receipt }\end{array}$ & $\begin{array}{l}\text { Review } \\
\text { Order }\end{array}$ & $\begin{array}{l}\text { Reviewed } \\
\text { Order }\end{array}$ & Chef \\
\hline Chef & $\begin{array}{l}\text { Reviewed } \\
\text { Order }\end{array}$ & Approval & $\begin{array}{l}\text { Accepted } \\
\text { Delivery }\end{array}$ & Manager \\
\hline Manager & $\begin{array}{l}\text { Accepted } \\
\text { Delivery, } \\
\text { Receipt }\end{array}$ & $\begin{array}{l}\text { Authorize, } \\
\text { Signature }\end{array}$ & $\begin{array}{l}\text { Signed } \\
\text { Receipt }\end{array}$ & Supplier \\
\hline
\end{tabular}

As shown in Table 1, the transaction is never entered on the system. Even more, there is no formal record of every business transaction (i.e., purchase) made in the restaurant, apart from the Receipt provided by the supplier. Solutions to the identified problems are shown on Table 2.

Table 2. Purchasing process recommended solutions

\begin{tabular}{|l|l|}
\hline Problem & Recommended Solution \\
\hline $\begin{array}{l}\text { No data is } \\
\text { entered on the } \\
\text { system }\end{array}$ & $\begin{array}{l}\text { Prepare catalogs for raw material capture on POS } \\
\text { System }\end{array}$ \\
\hline $\begin{array}{l}\text { No formal } \\
\text { record } \\
\text { keeping }\end{array}$ & $\begin{array}{l}\text { Use POS system to keep track of purchases, } \\
\text { suppliers and raw materials and their costs }\end{array}$ \\
\hline $\begin{array}{l}\text { Unneeded } \\
\text { "actor" }\end{array}$ & $\begin{array}{l}\text { Eliminate the need of the Cashier to send order to } \\
\text { supplier. Use POS systems order process, for record } \\
\text { keeping. }\end{array}$ \\
\hline $\begin{array}{l}\text { No Inventory } \\
\text { tracking }\end{array}$ & $\begin{array}{l}\text { Track purchase orders, product requirements, and } \\
\text { product waste management through POS system`s } \\
\text { Inventory module. }\end{array}$ \\
\hline
\end{tabular}

By creating a new System Catalogs with standardized Menu Items, Raw Materials, Suppliers, or Recipes that the enterprise needs, and integrating the existing POS and Management System into all operational processes, a more stable and faster operation can be achieved. Also, the data from all branches can be integrated into a single data warehouse for further analysis. A data cleanup process will be required to maintain historical records in the data warehouse, which will allow for data analysis to look for patterns, trends and customer behavior. All this has to be done while installing the POS software in a server with the requirements laid out by the software developer, to avoid having system outages, duplicate entries and for the server to be able to 
support the workload of the client terminals without delays in rush hours.

This first phase will be implemented at the current headquarters on, and it will be rolled out to all branches after the initial implementation.

\subsection{Challenges and opportunities}

At least in the case study presented, due to the background of owners, the restaurant has managed to survive the 2-year gap and grow at a steady rate for the last 6 years. Nonetheless, this has come with really high costs that could have been avoided if they had focused their efforts in planning and creating strategies based on facts and historical data, rather than only on experience and seemingly "good ideas".

Moving forward, and only after reviewing the information gathered through the investigation, the owners are starting to realize the need for reliable data and the usefulness of the POS software and administration systems that they already possess. Plans to formalize the different processes and job positions are already under way, but it could take longer than expected due to the "small family business" culture that has been around since its foundation.

With a minimal investment, the project can be rolled out on all branches, but cultural barriers will show up to be the biggest threat. Nonetheless, once the owners realize of the benefits of the implementation, said barriers can be surmounted with the aid of current managers and supervisors. This can be the case of several other SMEs in Mexico.

Management and higher corporate positions have been analyzing data to reinforce their business in the last few years. This was a watershed that marked the origin of what we now know as Business Intelligence, though on a very different scale. $\mathrm{BI}$ is not only focused on large companies but also on SMEs. Business Intelligence for SMEs is becoming a great revolution and a stimulus for small businesses to start addressing their strategies in the most effective way [12].

In a SME, unlike a large one, the need for specialized tools, extensive training and gigantic implementations are significantly reduced. Such companies operate by a set of rules and practices more equitable to those of its rivals. Also, because there are several "off-the-shelf" software solutions, its use and implementations are much simpler, pointing to the data sources available to start operating. Due to the fact that we can find BI solutions based on open source technologies focused on the end user, we do not need to consider overspending to implement a functional and effective solution. These tools are designed so that important business decisions can be made without the intervention of the IT area, streamlining processes and allowing immediate reaction to any event within the industry or market. Experience is what will drive most ordinary users to increasingly better results, as they become more used to using the tools needed for the company's growth, and a formal corporate culture begins to set in [13].

The effect caused by a good implementation of business intelligence is impressive. For example, the number of sources of information is usually scattered in any organization. The ability to have a single view of information, in addition to having scattered data integrated in reports, data from different dimensions and events in time; and having the power to solve questions that begin with "what if ..." are just some of the advantages of having BI tools [14].

\section{Closing remarks}

The most difficult part of a BI project is changing the culture of business owners and the people that have worked in similar SMEs for a long time: "If it's worked this well, why should we change it?" In the case study presented, the business owners are welleducated and this factor can be important for imminent changes in the near future.

In the case of Mexico, the country can benefit from having consolidated SMEs, but there are challenges and opportunities that need to be addressed. For this, Mexico needs stronger SMEs that can endure long enough to become Big Enterprises that use all the information that they can, taking advantage of a solid BI and Analytics solution and benefit from the information that they already generate.

\section{References}

[1] Rouibah, K., \& Ould-Ali, S. (2002). PUZZLE: a concept and prototype for linking business intelligence to business strategy. The Journal of Strategic Information Systems, 11(2), 133-152.

[2] Sabherwal, R. and I. Becerra-Fernandez, Business intelligence. 2009, Hoboken, N.J.; Chichester: Wiley; John Wiley [distributor].

[3] Murty, K.G., et al., A decision support system for operations in a container terminal. Decision Support Systems, 2005. 39(3): p. 309-332.

[4] Gutierrez Neyoy, J.E. Tecnologías de Información para los Negocios. 2015 September, 30th 2015 [cited 2016 July 7th]; Available from: http://edelgtz.blogspot.mx/.

[5] Trkman, P., et al., The impact of business analytics on supply chain performance. Decision Support Systems, 2010. 49(3): p. 318-327.

[6] IBM. Bayer optimiza sus operaciones con tecnología de IBM Argentina. 2013 [cited 2016 July 7th]; Available from: https://www03.ibm.com/marketing/ar/casos_de_exito/bayer/.

[7] Liddle, A. J. (2007). Above-store reporting benefits highlighted by FS/TEC panel. Nation's Restaurant News, 41(32), 50.

[8] Briggs, L. (2014). Bagel Chain Serves Up Happy Users with Move to Mobile Dashboards. Business Intelligence Journal, 19(3), 35-37.

[9] Rice, V. (2001). House Specialty: Fresh Data. Eweek, 18(27), 51.

[10] Hamanaka, K. (2014). El Pollo Nuevo. Orange County Business Journal, 37(4), 1.

[11] [ProMexico, PyMES, eslabón fundamental para el crecimiento en México. (n.d.). Retrieved July 12, 2016, from http://www.promexico.gob.mx/negociosinternacionales/pymes-eslabon-fundamental-para-elcrecimiento-en-mexico.html

[12] Rostek, K., Business Intelligence for SMEs. SMEs, 2010: p. 164.

[13] Raymond, L., Globalization, the knowledge economy, and competitiveness: a business intelligence framework for the development of SMEs. Journal of American Academy of Business, 2003, 3(1-2): p. 260-269. 
[14] Raymond, L. and F. Bergeron, Enabling the business strategy of SMEs through e-business capabilities: A strategic alignment perspective. Industrial Management \& Data Systems, 2008. 108(5): p. 577-595.

[15] Domenge, R., \& Belausteguigoitia, I. (2010, June 25). Nuevas PyMEs: Problemas y Recomendaciones | Dirección Estratégica [Business Magazine]. Retrieved July 13, 2016, from http://direccionestrategica.itam.mx/nuevas-pymesproblemas-y-recomendaciones/

[16] [16] Kelly, J. F. (2013, March 20). México necesita menos Pymes. Retrieved July 13, 2016, from

http://www.forbes.com.mx/mexico-necesita-menos-pymes/ 